Nuclear Instruments and Methods 175 (1980) 393-396

(c) North-Holland Publishing Company

\title{
A NEGATIVE ION SOURCE FOR ALKALI IONS
}

\author{
A. VERMEER and N.A. VAN ZWOL \\ Fysisch Laboratorium, Rijksuniversiteit, P.O. Box 80.000, Utrecht, The Netherlands
}

Received 15 April 1980

An ion source is described which delivers negative alkali ions. With this source, which consists of a duoplasmatron and a charge exchange canal with alkali vapour, negative $\mathrm{Li}, \mathrm{Na}$ and $\mathrm{K}$ ions are produced. The oven in which alkali metals are evaporated can reach temperatures up to $575^{\circ} \mathrm{C}$.

\section{Introduction}

In the present paper the modifications are described of a negative ion source published some years ago [1], necessary to make it suitable for the production of alkali ions. This source, with which more than ten years experience has been obtained, was originally developed for helium ions, but soon the source was also used for heavy ions. The required elements are introduced into the source in the gas or vapour phase. In most cases also an auxiliary gas, mostly hydrogen, is used. The ions are obtained by dissociation of the gas or of the compound in the discharge in the source. After extraction from the source, negative ions are produced by means of charge exchange in potassium vapour. In fig. 1 a drawing of the source is presented. The positive ion beam is obtained from a duoplasmatron (1) and focussed through the exchange canal (2). The fucussing system consists of the expansion cup (3) and the extraction electrode (4). The alkali vapour used for the charge exchange is obtained by heating potassium in the stainless steel container (5). The container is heated by radiation from a heater coil, which is placed inside a drum (6). The heat collected by the copper drum flows to the container and to the exchange canal. In this way potassium vapour flows into the canal without condensation on the wall.

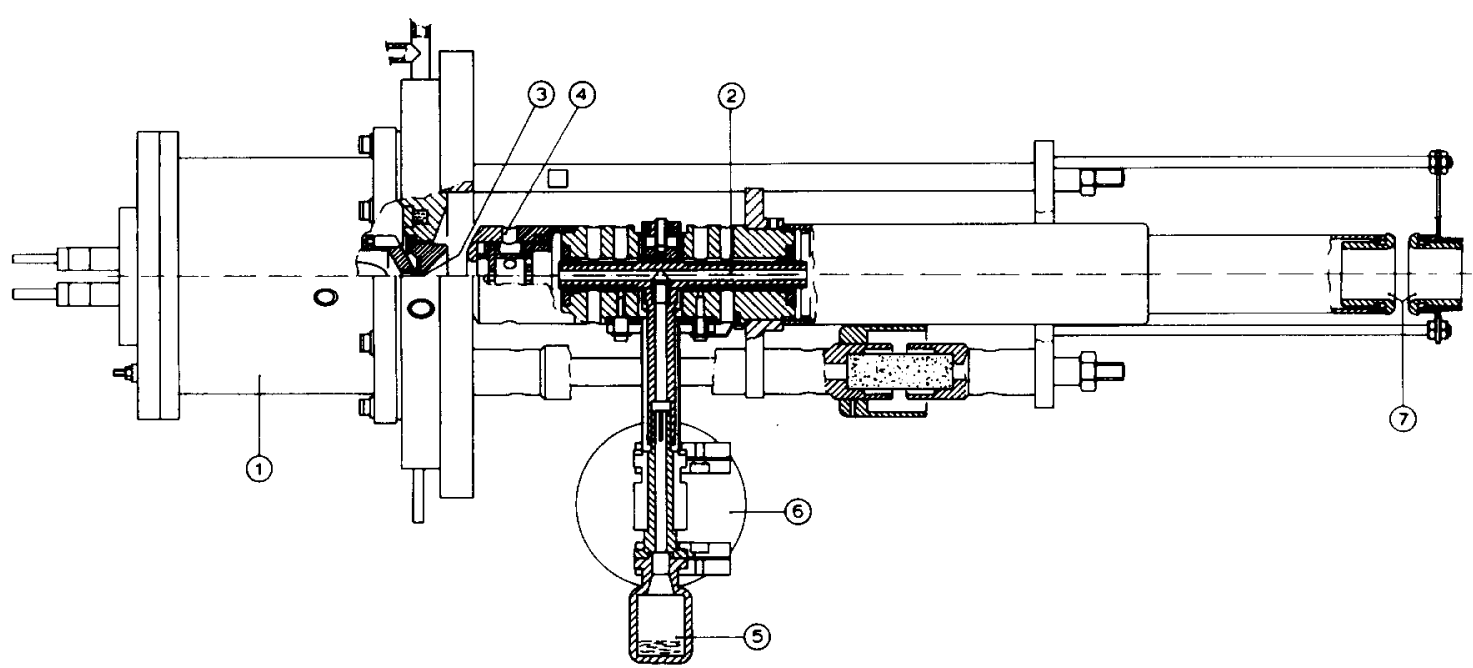

Fig. 1. Drawing of the negative ion source; $1=$ duoplasmatron, $2=$ exchange canal, $3=$ expansion cup, $4=$ extraction electrode, $5=$ potassium container, $6=$ copper drum, 7 = gap lens. 
Table 1

Ion currents produced by the ion source

\begin{tabular}{lll}
\hline Neg. ion & Source material & $\begin{array}{l}\text { Current L.E. } \\
\text { cup }(\mu \mathrm{A})\end{array}$ \\
\hline $\mathrm{H}$ & $\mathrm{H}_{2}$ & 2 \\
$\mathrm{He}$ & $\mathrm{He}$ & $1-3$ \\
$\mathrm{~B}$ & $\mathrm{BF}_{3}$ & 0.5 \\
$\mathrm{C}$ & $\mathrm{CO}_{2}$ & 5 \\
$\mathrm{~N}(\mathrm{NH})$ & $\mathrm{NH}_{4} \mathrm{OH}$ & 4 \\
$\mathrm{O}$ & $\mathrm{H}_{2} \mathrm{O}$ & 2 \\
$\mathrm{~F}$ & $\mathrm{SF}_{6}+\mathrm{H}_{2}$ & 1.5 \\
$\mathrm{Si}$ & $\mathrm{SiH}_{4}+\mathrm{H}_{2}$ & 1.5 \\
$\mathrm{P}$ & $\mathrm{PCl}_{3}$ & 1.5 \\
$\mathrm{~S}$ & $\mathrm{CS}_{2}+\mathrm{H}_{2}$ & 2.5 \\
$\mathrm{Cl}$ & $\mathrm{CCl}_{4}$ & 2 \\
\hline
\end{tabular}

After charge exchange the ion beam is again accelerated by the gap lens (7). The usual extraction voltage on the exchange canal is $12.5 \mathrm{kV}$, so the ions leave the source with an energy of $25 \mathrm{keV}$. For more details about the source see ref. 1 .

The ion currents which have been produced are summarized in table 1 . All the ions mentioned in the table are positively identified by means of nuclear reactions, after acceleration by the tandem.

The currents in the table, measured at the low energy (LE) cup are not always maximum obtainable values, but currents with which nuclear experiments are performed.

The duoplasmatron in the described form is not suitable to produce alkali ions. Therefore the source has to be modified such that alkali vapour can enter the arc discharge. Therefore the duoplasmatron must be provided with an oven, which can be heated up to sufficient high temperatures to provide alkali vapour $[2,3]$. The work of the Aarhus group [4] has shown that the charge exchange efficiency for alkali ions in alkali vapour has values, with which useful negative ion currents can be obtained. From this paper one can derive that the charge exchange efficiency for $\mathrm{Li}$ and $\mathrm{Na}$ at a potassium target has maximum values of $3 \%$ and $2 \%$, respectively. The maximum or near maximum values of the charge exchange are in the region of the extraction voltages of the present source, which is between 10 and $20 \mathrm{kV}$. For $\mathrm{K}$ at a cesium target, the maximum fraction is $1.5 \%$ at an energy of about $30 \mathrm{keV}$.

\section{A high-temperature duoplasmatron}

In the ion source the feed material must be put into the anodic plasma. In order to get solid materials as lithium, sodium and potassium into the discharge, the construction of the duoplasmatron at the side of the aperture plate was changed. Inside the expansion cup of the duoplasmatron a reservoir for the alkali metals was machined. By heating the expansion cup and thus the reservoir, alkali metal evaporates and enters the source via a narrow canal, just below the axis. In fig. 2 the construction of the duoplasmatron is shown schematically. Two heater elements are used each of $150 \mathrm{~W}$. The $110 \mathrm{~V}$ cartridge heater elements * have a length of $25.4 \mathrm{~mm}$ and a diameter of $6.35 \mathrm{~mm}$. To ensure a good heat contact, a clearance of only $0.02 \mathrm{~mm}$ is taken between the heater element and the hole in the low-carbon steel expansion cup. These holes are made by means of spark erosion. A thin layer of molykote is put onto the heating elements to prevent sticking on the wall of the hole. To diminish the loss of heat of the oven due to conduction, the expansion cup is put into a setting with a thermal resistor (see fig. 2). This thermal resistor is made of a thin stainless steel disk in the form of a labyrinth. The cup is held in position with the help of a bajonet catch. In this way the cup can easily be removed, for instance for a refill of the reservoir. To minimize also the heat losses via the intermediate electrode, the cone shaped top of this electrode is thermally insulated by means of small ceramic rings. The cone must be electrically connected to the housing of the duoplasmatron (see fig. 2). These ceramic rings in the magnetic circuit of the source do not have a disturbing influence on the functioning of the source. In fig. 3 a drawing of the construction at the anode side of the duoplasmatron is shown. The electrical feed throughs for the heating elements are on the highvacuum side of the ion source to prevent electrical breakdown between the leads. Fig. 4 shows the expansion cup with the holes for the heating elements and the reservoir in more detail. The cavity of the reservoir is obtained by milling and is thereafter closed by a lid, which is argon arc welded. Efforts to braze parts of the expansion cup with a $\mathrm{Au}(70)-$ $\mathrm{Cu}(16)-\mathrm{Ni}(14)$ alloy (melting range $960-1020^{\circ} \mathrm{C}$ ) failed, because lithium forms an alloy with copper at high temperature. This alloy easily diffuses through the soldering joint and solders the expansion cup in

\footnotetext{
* Watlow, St. Louis, U.S.A.
} 


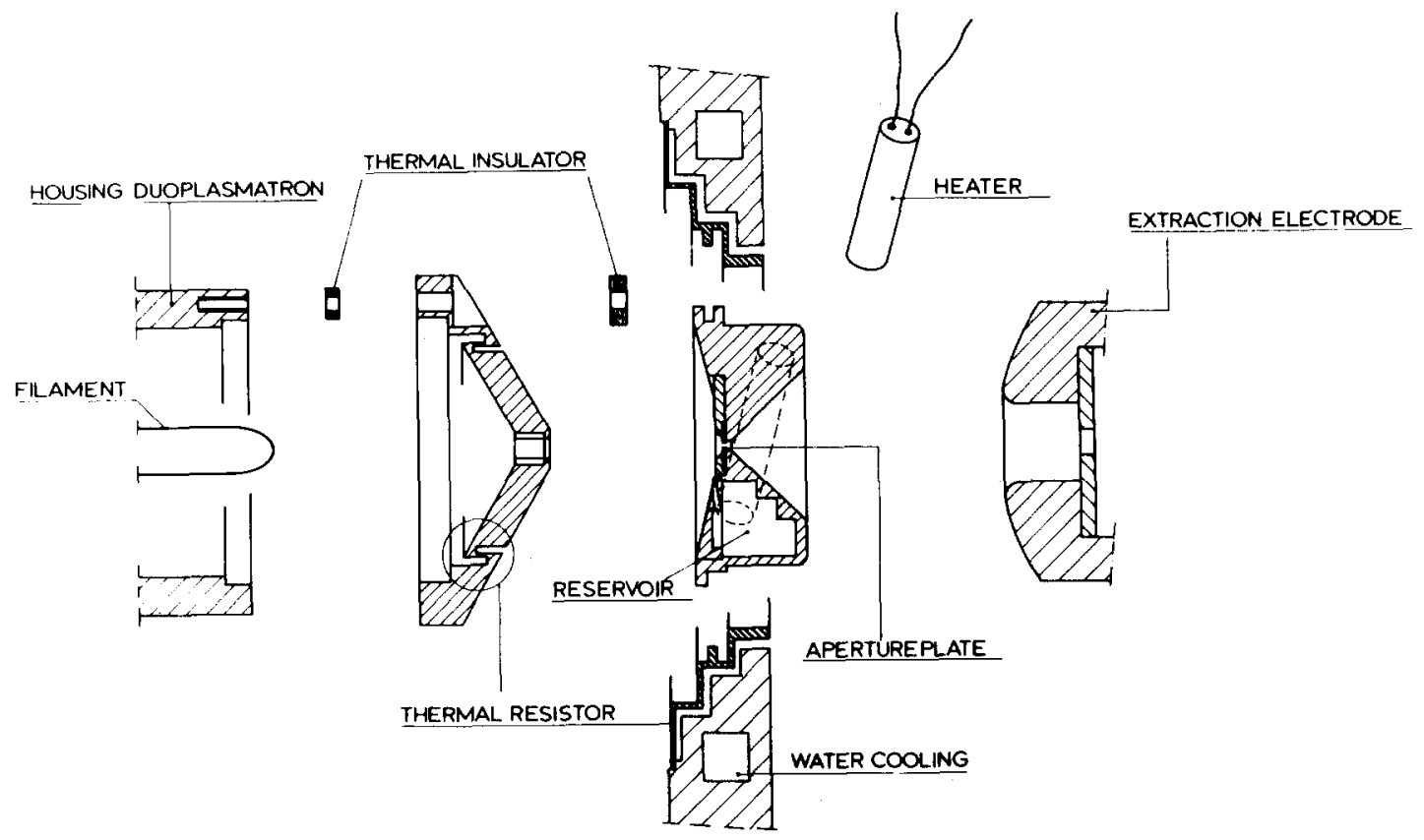

Fig. 2. Exploded view of the duoplasmatron equipped with an oven for alkali metals.

the bajonet catch. Removal of the expansion cup then becomes impossible. Inside the cup a hole is made for a thermocouple to measure the temperature. The maximum temperature which can be obtained is about $575^{\circ} \mathrm{C}$. The signal from the thermo-

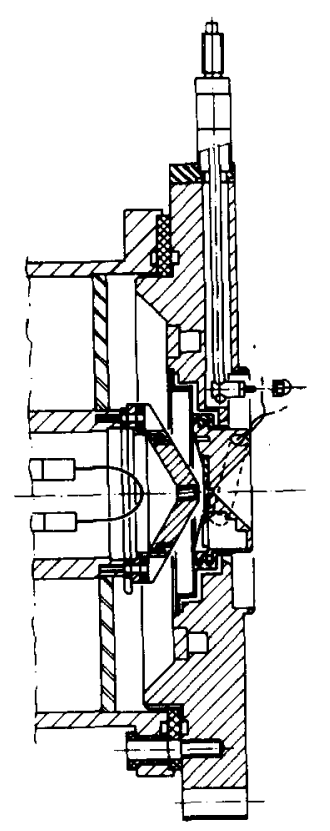

Fig. 3. Drawing of the duoplasmatron with an oven.
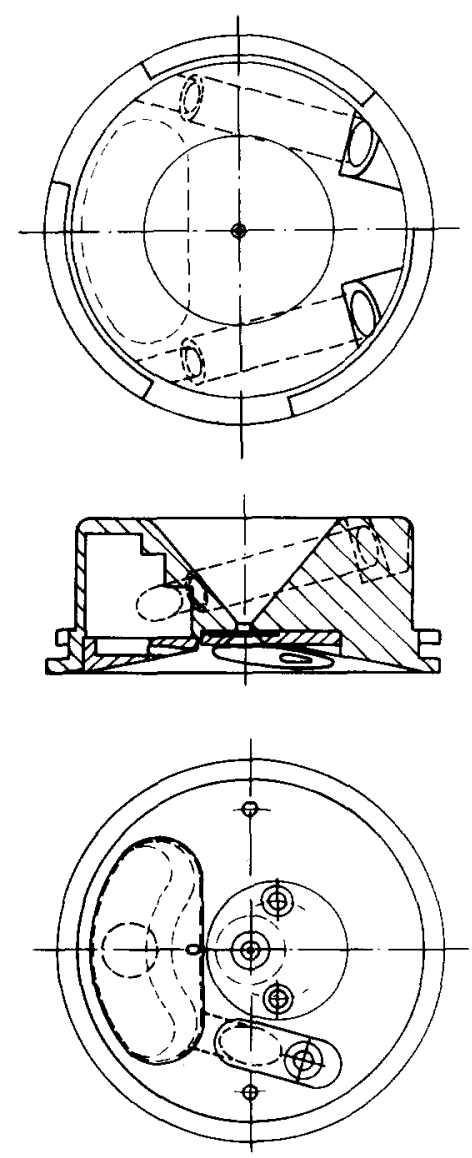

Fig. 4. Drawing of the extraction cone with reservoir. 
couple is used to stabilize the oven temperature with the help of an electronic-controlled power supply for the heater elements. With this stabilizer it is possible to stabilize the temperature within $5^{\circ} \mathrm{C}$, independent of the arc conditions of the source. The evaporated alkali metal is deposited on the holder parts of the ion source around the anode. This deposit material can easily be removed by means of water, forming lye.

\section{Results}

\subsection{Lithium}

A lithium beam was produced at an oven temperature of about $455^{\circ} \mathrm{C}$, with an extraction voltage of $12 \mathrm{kV}$. The beam current depends on the arc current of the ion source. At arc currents of some tenths of an ampere, beam currents of $0.5 \mu \mathrm{A}$ were produced. At higher arc currents, beam currents of more than $3 \mu \mathrm{A}$ were obtained. As auxiliary gas hydrogen was used in the source. The total source pressure was in the region of $0.1-0.2$ torr. The lithium consumption

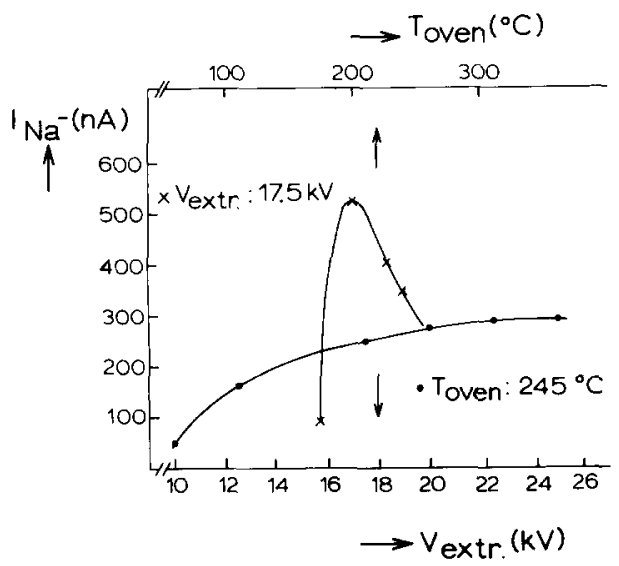

Fig. 5. Sodium beam current as a function of the extraction voltage and the temperature of the oven. was about $0.05 \mathrm{~g} / \mathrm{h}$. As exchange vapour potassium was used, and the temperature of the potassium container is held at $160^{\circ} \mathrm{C}$.

\subsection{Sodium}

A sodium beam can be produced under about the same conditions as for lithium. Only the temperature of the oven can be much lower. In fig. 5 the source current for sodium is plotted as a function of the extraction voltage and the temperature of the oven of the duoplasmatron.

\subsection{Potassium}

To produce a negative potassium beam cesium is used instead of potassium for charge exchange. As shown in ref. 4, cesium vapour has a not too low charge exchange efficiency for potassium ions. Also in this case hydrogen was used as auxiliary source gas at pressures of about 0.15 torr. The temperature of the oven was held between 130 and $140^{\circ} \mathrm{C}$. The negative potassium beams obtained were between 0.1 and $0.2 \mu \mathrm{A}$, at an extraction voltage of $16 \mathrm{kV}$. This is lower than the optimum voltage for charge exchange as can be seen in ref. 4 , but also other factors depending on the extraction voltage play a role, such as focussing through the exchange canal and voltage breakdown.

\section{References}

[1] A. Vermeer, N.A. van Zwol and B.A. Strasters, Nucl. Instr. and Meth. 106 (1973) 113.

[2] R. Masic, R.J. Warnecke and J.M. Sauter, 1st Int. Conf. on Les sources d'ions (Saclay, 1969) p. 387.

[3] J. Schulte in den Bäumen, J. Ilgan and B.H. Wolf, Proc. 2nd. Int. Conf. on Ion sources (Vienna, 1972) p. 549.

[4] P. Tykesson, Symp. Northeastern accelerator personnel, Oak Ridge (1978) and private communication. 